\title{
Opening of the Thorax
}

National Cancer Institute

\section{Source}

National Cancer Institute. Opening of the Thorax. NCI Thesaurus. Code C38631.

Either of two (upper and lower) openings in the chest. 